\title{
Developing herbicide tolerant transgenic plants for sustainable weed management
}

\begin{abstract}
Many learners of Arabic as a Foreign Language (AFL) in Malaysia lack the necessary skills and strategies to comprehend Arabic texts. It is important, thus, for Malaysian AFL learners to know how to read skilfully and to be able to deal with an Arabic text independently. Therefore, this study aims to explore the Malaysian AFL learners' major problems in reading Arabic texts and determine the appropriate set of design principles for effective strategic reading. The study employed a qualitative approach in which semi-structured interviews were conducted. The problems of AFL learners in reading were examined from a teaching perspective. The interview participants consist of a purposively selected sample of five Arabic language experts from the International Islamic University Malaysia (IIUM). The study found that the AFL learners “ approach towards Arabic reading is similar to those described in the previous studies as poor comprehension and lack of reading skills. Based on these findings, design principles for effective strategic reading were developed. These design principles represent a significant contribution to the development of Arabic reading, particularly in the Malaysian context.
\end{abstract}

Keyword: Arabic; Foreign language; Design principles; Malaysia; Reading skills; Strategic reading; University students 